\title{
Revisional bariatric surgery: An update
}

\author{
Isabelle Debergh, ${ }^{1}$ Bruno Dillemans, ${ }^{1,2}$ \\ 'Department of General, AZ Sint Jan AV, Ruddershove, 10, 8000 Brugge, Belgium \\ ${ }^{2}$ Pediatric and Vascular Surgery, AZ Sint Jan AV, Ruddershove, 10, 8000 Brugge, Belgium
}

\begin{abstract}
Obesity can be defined as a chronic disease with a serious impact on an individual's quality of life; moreover, it is a leading risk factor for global death. Bariatric surgery has already proven its efficacy in providing the patient with a healthier life. Nonetheless, failure of initiated treatment can occur in medical practice. We can and should offer our patients correct, patient-tailored revisional therapy conducted by an experienced surgeon in a high-volume hospital facility. In this article, current indications and strategies for secondary bariatric procedures were summarized.
\end{abstract}

Keywords: Duodenal Switch; revisional bariatric surgery; Roux en Y gastric bypass; single anastomosis gastric bypass; sleeve gastrectomy.

\section{Introduction}

According to the World Health Organization (WHO), more than 500 million adults world wide or $11 \%$ of the population at the age of 20 and older were obese in 2008. Since then, 3.5 million adults have died each year as a result of being obese or overweight. ${ }^{[1]}$ Moreover, serious morbidities are related to obesity like the burden of diabetes, ischemic heart disease and cancer. At this point, unfortunately, obesity is linked to more global deaths than the underweight. In low- and middle income countries, the problem of obesity is rapidly rising to the levels of high-income countries. Another disturbing evolution in developing countries can be seen in younger populations, with a 30\% increase of childhood obesity compared to developed countries. Globally, 42 million children under the age of 5 were overweight or obese in 2013. Therefore, WHO developed a Global Strategy on Diet, Physical Activity and Health with the aim of halting global obesity rates by 2020 . This action plan formulates advice for an individual patient, societal measures, and food industry to prevent and cure this chronic disease. The responsibility of having an easily accessible healthcare system, not only for preventing overweight, but also for curing obesity is not discussed. In this setting, bariatric surgery has already proven its efficacy and was found to be more effective than non-surgical treatment methods in achieving weight loss and remission of comorbidities. ${ }^{[2]}$ A patient-tailored approach for choosing the best surgical strategy is initially necessary to cure the patient in the long term. However, when this therapy fails, a revisional operation can be offered in well-selected patients.

\section{Motivation and Indication for Revisional Bariatric Surgery}

The problem of failed bariatric procedures is multifactorial. Before proposing bariatric surgery in the first place as 
a primary treatment for obesity, every patient should be worked-up in a multidisciplinary team. A patient-tailored approach can lead to better outcomes in weight loss and morbidity relief in the long term. For instance, patients with co-morbidities related to metabolic syndrome will have proven to benefit after performing Roux-en-Y gastric bypass (RYGB), and in patients presenting with reflux disease, RYGB might also be the first choice procedure. ${ }^{[3]} \mathrm{On}$ the contrary, sleeve gastrectomy will be the preferred primary treatment in case of osteoporosis, dumping symptoms, or vitamin deficiencies.

Consequently, weight or morbidity recidivism, or anatomical/technical complications can be related to an inappropriate primary surgical strategy, but also to changes in surgical knowledge and techniques, or patient related factors. An inconsistent definition of failure of a primary bariatric procedure is the reason of heterogeneous numbers in the reported literature. The most frequently used definition of failure of the initial operation is $<50 \%$ of excess weight lost (EWL), with or without a BMI of $>35 \mathrm{~m} /$ $\mathrm{kg}^{2}$ at 18 months post-operatively. ${ }^{[4]}$ None of the reviewed articles described failure of remission of type 2 diabetes or hypertension as an indication for reoperation.

Henry Buchwald has stated recently that revisional bariatric surgery is a moral obligation to the patient with a failed bariatric procedure. ${ }^{[5]}$ This expressed indignation arouse in a climate of negative responses to revisional bariatric surgery manifested in the US healthcare system. However, evidence-based literature supports a reoperation strategy for conversion or correction of acute or chronic complications after failed bariatric surgery. An improved weight loss, reduction in comorbidities, and resolution of complications is achieved after re-intervention. ${ }^{[6,7]}$

\section{Revision of LAGB}

High rates of failure in weight loss due to maladaptive eating, and band-related complications such as slippage, tubing leakage, esophageal motility disorders (and pseudo achalasia)are reasonswhy placing a laparoscopic adjustable band (LAGB) has almost currently become obsolete as primary bariatric treatment. A few studies have reported success rates in converting LAGB to sleeve gastrectomy when performed in a one-or a two-step procedure, ${ }^{[8,9]}$ but overall, RYBG is the revisional procedure of choice. In most cases, conversion to RYGB can be performedin a one-step procedure. ${ }^{[10-12]}$ In the postoperative fifth year, revisional RYGB provides good additional weight loss and similar rates of improvement and remission of coexisting conditions compared to primary RYGB. ${ }^{[13]}$

\section{Revision of VBG}

Reasons for re-intervention of vertical banded gastroplasty (VBG) have been described to be unsatisfactory weight loss, emesis, pyrosis and maladaptive eating. Band erosions, pouch or esophageal dilatation, stapler line dehiscence, and band-related stenosis are reported anatomical complications, for which RYGB is considered as the preferred revisional procedure ${ }^{[14,15]}$ although some report also acceptable results with conversion to sleeve gastrectomy. ${ }^{[8]}$ As most patients suffer from reflux and established maladaptive eating, we can not support sleeve gastrectomy or pouchogastrostomy as revisional options after failed VBG.

\section{Revision of SG}

Sleeve gastrectomy (SG) can be considered a primary procedure or the first restrictive step of a 2-step bariatric therapy. Inadequate weight loss is an important reason for re-intervention, but severe stenosis or reflux $(20 \%$ of patients after SG) can also form the motivation for conversion to RYGB ${ }^{[16]}$ if endoscopic therapy fails. ${ }^{[17]}$ In rare cases, conversion to RYBG can be the solution for chronic gastric fistula after $\mathrm{SG}{ }^{[14]} \mathrm{A}$ recent systematic review concerning failed sleeve gastrectomy due to inadequate weight loss has concluded that both RYGB or re-sleeve gastrectomy are appropriate procedures with similar weight loss outcomes after 24 months, ${ }^{[18]}$ depending on whether malabsorption or more restriction has to be added.

Each decision has to be tailored depending on a specific case. Other strategies can include conversion to a classic duodenal switch operation (with Roux-en-Y configuration) or tosingle anastomosis duodeno-ileal bypass with sleeve gastrectomy (SADI-S) to add malabsorption, with good results in primary cases in terms of additional weight loss and normalization of HbA1c levels in diabetic patients. ${ }^{[19,20]}$ In 2002, Santoro et al. developed a procedure combining sleeve gastrectomy with enterectomy thatretains the first 50 to $100 \mathrm{~cm}$ of jejunum and the last 200 to $250 \mathrm{~cm}$ of the ileum ${ }^{[21]}$ and also reported good initial weight loss. An important goal with this type of interventions is to change neuroendocrine responses in bariatric patients, which is also targeted in sleeve gastrectomy with ileal transposition. Although it is interesting, these new developments currently lack evidence, and can only be used in well selected cases and in experienced hands. 


\section{Revision of RYGB}

Severe dumping symptoms or invalidating hypoglycemic episodes, refractory to any conservative therapy, can sometimes be the reasons to convert a RYGB to normal anatomy or SG. More frequently, inadequate weight loss after RYGB or weight recidivismis the cause for considering alternative surgery. Options includeeither conversion of RYGB to duodenal switch, distal bypass, adjustable banding, pouch revision, or endoscopic procedures. Endoscopic gastric plication results in weight regain after one year, and is not generally accepted as treatment strategy. ${ }^{[22]}$ In selected patients with increased caloric intake or dilated gastrojejunostomy, favorable results have been described adding LAGB. ${ }^{[23]}$ Other cases with anatomical gastric pouch enlargement on barium esophagograms can benefit from performing gastric pouch or gastrojejunal revision, leading to significant weight loss one year after revisionalsurgery. ${ }^{[2]}$ In patients known to have low caloric intake $(<1500 \mathrm{kcal} /$ day), without vitamin deficiencies or anatomical deformities, a laparoscopic lengthening of the Roux limb ${ }^{[25]}$ or biliopancreatic limb in case of failed RYGB ${ }^{[26]}$ will offer good additional weight loss.

\section{Revisions of BPD}

In case of weight regain afterbiliopancreatic diversion (BPD), pouch revision will be necessary. On the other hand, nutritional deficiencies, underweight, and frequent mal-absorptive diarrhea after BPD will be the motivation for offering the patient a re-intervention. These adverse effects can consequently lead to a serious decrease in quality of life, despite good weight loss results. Conversion with lengthening of the common limbby reconnecting the alimentary limb proximal on the biliopancreatic limbis the solution to these problems. ${ }^{[27]}$ Often, this revisional procedure cannotbe performed laparoscopically, and the open procedure will result in longer hospital stay. Postoperative ileus will also be influenced by the laborious activation of peristalsis in a formerly inactive part of bowel (biliopancreatic limb).

\section{Approach: Open vs Laparoscopic vs Robotic?}

Revisional surgery is always technically challenging for the bariatric surgeon. These operations carry the possibility for a staged approach or conversion, and a higher risk of complications. This is due tothe presence of scarring, adhesions and inflammation with difficulties of identifying anatomical landmarks, and harming vascular supply, which will increase the risk of bleeding and anastomotic complications. A safe approach is necessary using the preferred conventional laparoscopic approach. This minimally invasive technique has the advantage of giving a good two-dimensional presentation of the region of the upper gastrointestinal tract. However, if this operative strategy is not safe, open surgery must be considered. Nowadays, robotic surgery is also being used for revisional bariatric surgery, leading to a three-dimensional vision, and amplified dexterity of the surgeon. In highly selected cases and in experienced hands, these robot-assisted interventions are reported to be safe and effective, without causing higher costs In the long term. ${ }^{[28]}$ Currently, general evidence to use a robotic approach in revisional bariatric surgery is lacking, as only small case series have been reported. Moreover, this technique is still very cumbersome, which is illustrated in the study of Bindal et al. as the mean operative time for robotic revisionalRYGB was $226 \pm 45.3 \mathrm{~min}$. Therefore, we can conclude that laparoscopy for bariatric re-interventions remains the preferred approach.

\section{Conclusion}

The worldwide problem of overweight and obesity demands a multifactorial approach. Obesity has to be considered a chronic disease, in which bariatric surgery is an evidence-based therapeutic option with excellent results on excessive weight loss and remission of co-morbidities. ${ }^{[2]}$ Nonetheless, some individuals will be refractory to initiated treatment or will present with complications or adverse effects. We need to offer an alternative therapy to this group of patients. In experienced hands, revisional bariatric surgery can be performed laparoscopically in a safe way with low complication ratesand excellent results on additional weight loss. ${ }^{[29,30]}$

If metabolic surgeons want to gather and keep support in the provider community, they have the responsibility to report the results of primary and secondary bariatric procedures, hospitalization, complication rates and healthcare costsin a standardized way. There is need to reduce invasiveness of bariatric therapy and re-interventions in the futureto enhance societal support, and more importantly, to enable the treatment of more individuals.

\section{Disclosures}

Peer-review: Externally peer-reviewed.

Conflict of Interest: None declared. 


\section{References}

1. World Health Organization: Obesity Facts. http://www.who. int/me diacentre/factsheets/fs311/en/ (accessed January 11, 2015).

2. Gloy VL, Briel M, Bhatt DL, Kashyap SR, Schauer PR, Mingrone $\mathrm{G}$, et al. Bariatric surgery versus non-surgical treatment for obesity: a systematic review and meta-analysis of randomised controlled trials. BMJ 2013;347:f5934. [CrossRef]

3. Lannoo M, Dillemans B. Laparoscopy for primary and secondary bariatric procedures. Best Pract Res Clin Gastroenterol 2014;28:159-73. [CrossRef]

4. Mann JP, Jakes AD, Hayden JD, Barth JH. Systematic review of definitions of failure in revisional bariatric surgery. Obes Surg 2015;25:571-4. [CrossRef]

5. Buchwald H. Revisional metabolic/bariatric surgery: a moral obligation. Surg Obes Relat Dis 2014;10:1019-21. [CrossRef]

6. McKenna D, Selzer D, Burchett M, Choi J, Mattar SG. Revisional bariatric surgery is more effective for improving obesity-related co-morbidities than it is for reinducing major weight loss. Surg Obes Relat Dis 2014;10:654-9. [CrossRef]

7. Brethauer SA, Kothari S, Sudan R, Williams B, English WJ, Brengman $\mathrm{M}$, et al. Systematic review on reoperative bariatric surgery: American Society for Metabolic and Bariatric Surgery Revision Task Force. Surg Obes Relat Dis 2014;10:952-72.

8. Iannelli A, Schneck AS, Ragot E, Liagre A, Anduze Y, Msika S, et al. Laparoscopic sleeve gastrectomy as revisional procedure for failed gastric banding and vertical banded gastroplasty. Obes Surg 2009;19:1216-20. [CrossRef]

9. Noel P, Schneck AS, Nedelcu M, Lee JW, Gugenheim J, Gagner $M$, et al. Laparoscopic sleeve gastrectomy as a revisional procedure for failed gastric banding: lessons from 300 consecutive cases. Surg Obes Relat Dis 2014;10:1116-22.

10. Aarts E, Koehestanie P, Dogan K, Berends F, Janssen I. Revisional surgery after failed gastric banding: results of onestage conversion to RYGB in 195 patients. Surg Obes Relat Dis 2014;10:1077-83. [CrossRef]

11. Thereaux J, Veyrie N, Barsamian C, Corigliano N, Beauchet A, Poitou $C$, et al. Similar postoperative safety between primary and revisional gastric bypass for failed gastric banding. JAMA Surg 2014;149:780-6. [CrossRef]

12. Emous $M$, Apers J, Hoff $C$, van Beek AP, Totté E. Conversion of failed laparoscopic adjustable gastric banding to Rouxen-Y gastric bypass is safe as a single-step procedure. Surg Endosc 2015;29:2217-23. [CrossRef]

13. Thereaux J, Corigliano N, Poitou C, Oppert JM, Czernichow S, Bouillot JL. Five-year weight loss in primary gastric bypass and revisional gastric bypass for failed adjustable gastric banding: results of a case-matched study. Surg Obes Relat Dis 2015;11:19-25. [CrossRef]

14. Shimizu H, Annaberdyev S, Motamarry I, Kroh M, Schauer PR, Brethauer SA. Revisional bariatric surgery for unsuccessful weight loss and complications. Obes Surg 2013;23:1766-73.

15. Vasas $P$, Dillemans $B$, Van Cauwenberge $S$, De Visschere $M$, Vercauteren C. Short- and long-term outcomes of vertical banded gastroplasty converted to Roux-en-Y gastric by- pass. Obes Surg 2013;23:241-8. [CrossRef]

16. Himpens J, Dobbeleir J, Peeters G. Long-term results of laparoscopic sleeve gastrectomy for obesity. Ann Surg 2010;252:319-24. [CrossRef]

17. Ferrer-Márquez M, Belda-Lozano R, Solvas-Salmerón MJ, Ferrer-Ayza M. Revisional surgery after laparoscopic sleeve gastrectomy. Surg Laparosc Endosc Percutan Tech 2015;25:6-9.

18. Cheung D, Switzer NJ, Gill RS, Shi X, Karmali S. Revisional bariatric surgery following failed primary laparoscopic sleeve gastrectomy: a systematic review. Obes Surg 2014;24:1757-63.

19. Topart P, Becouarn G, Ritz P. Weight loss is more sustained after biliopancreatic diversion with duodenal switch than Roux-en-Y gastric bypass in superobese patients. Surg Obes Relat Dis 2013;9:526-30. [CrossRef]

20. Sánchez-Pernaute A, Herrera MA, Pérez-Aguirre ME, Talavera $\mathrm{P}$, Cabrerizo $\mathrm{L}$, Matía $\mathrm{P}$, et al. Single anastomosis duodeno-ileal bypass with sleeve gastrectomy (SADI-S). One to three-year follow-up. Obes Surg 2010;20:1720-6. [CrossRef]

21. Santoro S, Malzoni CE, Velhote MC, Milleo FQ, Santo MA, Klajner S, et al. Digestive Adaptation with Intestinal Reserve: a neuroendocrine-based operation for morbid obesity. Obes Surg 2006;16:1371-9. [CrossRef]

22. Ong'uti SK, Ortega G, Onwugbufor MT, Ivey GD, Fullum TM, Tran DD. Effective weight loss management with endoscopic gastric plication using StomaphyX device: is it achievable? Surg Obes Relat Dis 2013;9:113-7. [CrossRef]

23. Irani K, Youn HA, Ren-Fielding CJ, Fielding GA, Kurian M. Midterm results for gastric banding as salvage procedure for patients with weight loss failure after Roux-en-Y gastric bypass. Surg Obes Relat Dis 2011;7:219-24. [CrossRef]

24. Hamdi A, Julien C, Brown P, Woods I, Hamdi A, Ortega G, et al. Midterm outcomes of revisional surgery for gastric pouch and gastrojejunal anastomotic enlargement in patients with weight regain after gastric bypass for morbid obesity. Obes Surg 2014;24:1386-90. [CrossRef]

25. Brolin RE, Cody RP. Adding malabsorption for weight loss failure after gastric bypass. Surg Endosc 2007;21:1924-6.

26. Himpens J, Coromina L, Verbrugghe A, Cadière GB. Outcomes of revisional procedures for insufficient weight loss or weight regain after Roux-en-Y gastric bypass. Obes Surg 2012;22:1746-54. [CrossRef]

27. Hamoui N, Chock B, Anthone GJ, Crookes PF. Revision of the duodenal switch: indications, technique, and outcomes. J Am Coll Surg 2007;204:603-8. [CrossRef]

28. Bindal V, Gonzalez-Heredia R, Elli EF. Outcomes of Robot-Assisted Roux-en-Y Gastric Bypass as a Reoperative Bariatric Procedure. Obes Surg 2015;25:1810-5. [CrossRef]

29. Deylgat B, D'Hondt M, Pottel H, Vansteenkiste F, Van Rooy $F$, Devriendt D. Indications, safety, and feasibility of conversion of failed bariatric surgery to Roux-en-Y gastric bypass: a retrospective comparative study with primary laparoscopic Roux-en-Y gastric bypass. Surg Endosc 2012;26:1997-2002.

30. Van Dessel E, Hubens G, Ruppert M, Balliu L, Weyler J, Vaneerdeweg W. Roux-en-Y gastric bypass as a re-do procedure for failed restricive gastric surgery. Surg Endosc 2008;22:1014-8. [CrossRef] 